\title{
Design of Wet Leak Test Machine for Radiators: A Study
}

\author{
Darshan Dabholkar*, Dipak Shenvi, Nitinkumar Anekar³,Onkar Joshi \\ ${ }^{1}$ Department of Mechanical Engineering, MITCOE, Savitribai Phule Pune University, Pune, India
}

Accepted 02 March 2016, Available online 15 March 2016, Special Issue-4 (March 2016)

\begin{abstract}
This paper gives study of design of a wet leak test machine, used for the detection of leakages in radiators. It is based on the technique of submerging the part in the water that is stored in an immersion tank. Immersion tanks are a widely used method for location of leakages in complex assemblies and products. The part under test is pressurized with air while being submerged in a liquid, typically water. The operator looks for a stream of bubbles indicative of a leak. Proper selection and implementation of a production leak test method starts with an understanding of why the test is being performed, followed by establishing what the leak rate limit is, and finally a determination of how the leak test will be performed.
\end{abstract}

Keywords: leak test, immersion tank, stream of bubbles, sensitivity, cost effective and reliable

\section{Introduction}

There is a wide scope for the wet leak testing machine, especially in automobile and refrigeration industries. In the refrigeration industry, components and systems must be leak tested to ensure that refrigerant leakages are below specified limits. The three basic functions of leak testing are

- Detection of leakages

- Measurement of leak rate and

- Location of leakages

There are many methods and types of test equipment for solving these problems, but there is no single technique that fits every situation. Each test method is suitable only for a specific leak rate or for fixed forms and technologies

In most instances where leak detection is used, explicit leak rate measurement is not required, but the system must be able to recognize if the leak rate is above or below a specified level. This reference limit depends on the maximum acceptable leak rate, consistent with the reasonable working life expectation for final products, and, especially in certain countries, on rules and regulations constraints.

A leak test procedure is usually a quality control step to assure device integrity, and should preferably be a one-time non-destructive test, without impact on the environment and operators. Several leak-testing techniques are available, spanning from very simple approaches to systems that are more complex. The most commonly used leak test method is the

*Corresponding author: Darshan Dabholkar underwater bubble test. It is a wet leak testing method. It consists of immersing a pressurized part, usually with high-pressure dry air or nitrogen, in a water tank and watching for the escaping bubbles. The larger and more frequent the bubbles, the bigger the leakage. The various machines used for leak testing of radiators are:

- Helium leak test machine

- Metal casting leak test machine

- Air decay leak test machine

- Dry leak test machine

The wet leak test machine is generally preferred over the other types because of the ease of testing and overall simplicity of the operation.

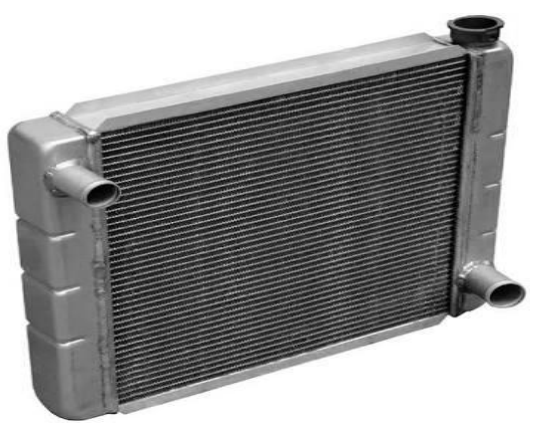

Fig.1. Radiator

\section{Wet leak test machine}

Once a leak rate limit or specification has been determined one can take a closer look at the available 
test methods to implement. However, the leak rate limit is not the only criteria that might affect the test method chosen. Here are some other considerations:

- What additional product cost (including production time) due to the leak test step can be tolerated?

- Based on an understanding of part design and manufacturing processes, what are the potential causes and locations of leaks?

- The simplest of the test methods, wet leak testing also called bubble immersion leak testing is typically the lowest cost method as well. In simple terms, the part under test is pressurized with air while being submerged in a liquid, typically water. The operator looks for a stream of bubbles indicative of a leakage.

- Automotive radiators often are checked for leaks this way. If a leak is present, the bubbles indicate where and the leak can be repaired.

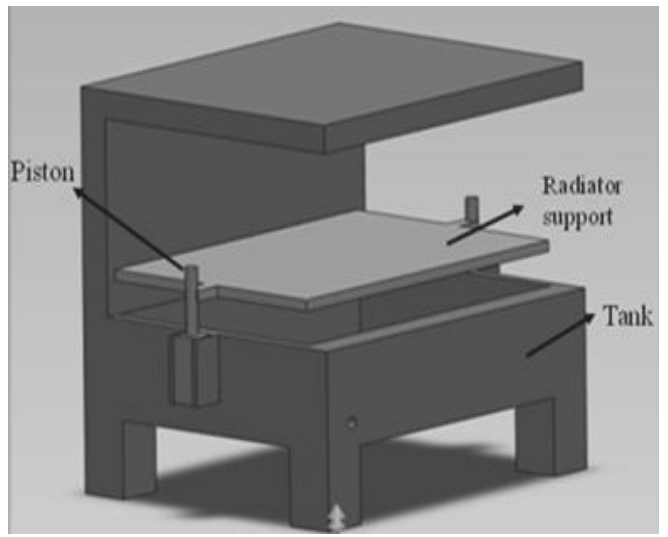

Fig 2 3D model of the machine

The vital features of this method are

- Radiators are not subjected to compressive loads, as flange to flange type clamping system is adopted.

- Easy loading of radiator and pneumatic clamping system for sealing between dummy tank and body.

- Dipping of the radiator in water by using piston and cylinder arrangement.

- Pneumatic system for imparting controlled air pressure and the display of pressure holding time.

- The sensitivity of this method can be better than the pressure decay method $\left(10^{\wedge} 4 \mathrm{~atm} \mathrm{cc} / \mathrm{sec}\right)$, and even faster for large parts.

Here are several variations of this method including: using liquids other than water, using vacuum to reduce the water pressure on the part, manually apply a liquid solution to the part instead of immersing it. The main limitation of this method is sensitivity, which is the minimum detectable leak rate. Considering a spherical bubble of radius $R$, its internal volume is given as,

$V=\frac{4}{3} \pi R^{3}$
- What cycle time for the leak test is acceptable and how will the leak test process fit in the production line?

- Will the parts be $100 \%$ tested, batch tested, or tested individually?

- What design and manufacturing limitations (pressure limits, part cleanliness, part temperature, and part rigidity) might affect the type of test method we use?

Let $\mathrm{p}$ be the pressure inside the bubble and $t$ be the time required to form the first bubble, then the sensitivity $\mathrm{S}$ is given as,

$S=\frac{p \times V}{t}$

The two key parameters influencing the sensitivity of this method are the smallest bubble detected by the operator and the waiting time for the bubble generation. This time must be compatible with the production rate and operator attention.It is reasonable to consider that the smallest bubble an operator can detect has $1 \mathrm{~mm}$ radius and that the waiting time is 30 seconds. Assuming that the pressure inside the bubble is atmospheric pressure, it can be stated from the previous equations that the bubble volume is $V=4.2 \mathrm{x}$ $10^{-6} \mathrm{~m}^{3}$, and thus the minimum detectable leak rate is $S=4.18 \times 10^{-5} \mathrm{~Pa}^{3} \mathrm{~m}^{3} \mathrm{~s}$. This is a theoretical value, but the real sensitivity is strongly influenced by external factors like illumination, water turbidity, unit location and placement and water movement. Some tricks can be used to improve this method

- Increasing the internal pressure in increments may increase the probability of finding a leak and reduce the time required for the process.

- A detergent can be added to the water to decrease its surface tension, which helps in preventing the leaking gas from clinging to the side of the component.

- Hot water in the tank sometimes helps in increasing the pressure inside the component or piping system. This increases the chance of detecting a leakage.

This technique offers leakage detection accuracy in the $10^{-3} \mathrm{~Pa}^{3} \mathrm{~m}^{3} / \mathrm{s}$ range. It is especially useful in high volume applications, and leak detection and location is very economical. However it has certain limitations like relatively low sensitivity, operator dependency, and a possibility of part contamination. Overall it is 
very widely used method, especially in the automotive industries for testing of radiators.

\section{Study of Pneumatic Circuit}

The pneumatic circuit diagram for wet leak test machine is given in Fig.3.Pressing the start pushbutton sends a signal to switch the air piloted valve on. The valve output is connected to the device to be controlled and to the timer control port. When the timer reaches its set time it sends a signal back to the air pilot valve resetting it, turning off the output to the device. To stop the timing (ie. emergency stop) press the stop button, which sends a signal via the "OR" logic valve to reset the double air piloted valve.

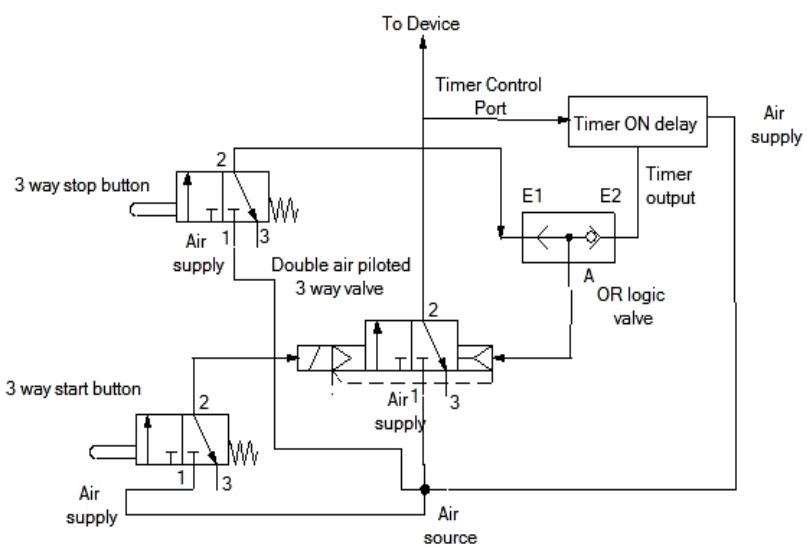

Fig. 3 Pneumatic circuit

The table below describes the functions of the various parts of the pneumatic circuit.

Table 1 Components of pneumatic circuit

\begin{tabular}{|c|c|c|}
\hline $\begin{array}{c}\text { S. } \\
\text { No. }\end{array}$ & Component Name & Description \\
\hline 1 & $\begin{array}{c}\text { Start button (push } \\
\text { type) }\end{array}$ & $\begin{array}{c}\text { For switching on the timer } \\
\text { circuit and thus beginning the } \\
\text { actuation }\end{array}$ \\
\hline 2 & $\begin{array}{c}\text { Double Air Piloted } \\
\text { Valve 3 way }\end{array}$ & $\begin{array}{c}\text { To redirect the air to the timer } \\
\text { and the main piston }\end{array}$ \\
\hline 3 & Timer & $\begin{array}{c}\text { To hold on the piston actuated } \\
\text { by using preset delay }\end{array}$ \\
\hline 4 & OR logic valve & $\begin{array}{c}\text { Function in OR logic to help } \\
\text { functioning of Stop button } \\
\text { along with that of timer output }\end{array}$ \\
\hline 5 & $\begin{array}{c}\text { Stop button(push } \\
\text { type) }\end{array}$ & $\begin{array}{c}\text { To stop the circuit } \\
\text { immediately when the process } \\
\text { is going on(in case of an } \\
\text { emergency) }\end{array}$ \\
\hline
\end{tabular}

\section{Design of machine components}

The wet leak test machine component design is given as below:

\subsection{Platform}

Platform is the component which is going to sustain the load of the radiator. Considering the compressive strength criterion, we selected SS304 as the material of the platform. The driving force behind this selection was the load bearing capacity of SS304. In addition to this SS304 has excellent weldability, formability and machinability. We have decided to reduce the crosssectional area by cutting out a number of strips from the platform. This will ensure that the final structure becomes lighter. The area ,volume, mass of platform is given as,

$A_{p}=W_{r}\left(\frac{F O S}{\sigma_{c}}\right)$

$V_{p}=A_{p} \times T$

Where,

$V_{r}=V_{p}$-Volume of intermediate strips

$m_{p}=\rho \times V_{r}$

\subsection{Piston}

The piston rod will bear the load of the platform and the radiator, and will be actuated by using the pneumatic timer circuit (as explained in the earlier section).Considering the amount of load to be sustained, we have selected SAE1045 as the material of the piston rod. Determination of the piston rod diameter will be on the basis of the load to be carried by it. Further selection of the piston-cylinder arrangement will be with reference to the standard Festo charts for pneumatic components. The bore diameter is given as,

$d_{b}=\sqrt{\frac{2 \times F O S \times g \times\left(m_{r}+m_{p}\right)}{\pi}}$

\subsection{Tank}

The tank is a very critical component of this machine structure. It is used to store the water in which the radiator-platform assembly will be immersed to detect the leakages present in the radiator. It should have enough strength to sustain the pressure exerted by the required volume of water, around 500litres.Considering this we have selected SS304 as the material for tank. It has excellent corrosion resistance and prevents inter-granular corrosion as well. Overall it gives a pretty solid all-round performance within economical limits. The tank thickness is given as,

$$
T^{\prime}=L \sqrt{\frac{\beta \times \rho_{w} \times g \times H}{\sigma}}
$$

\section{Advantages, disadvantages and applications}

Given below are the advantages, disadvantages and applications of the wet leak test machine: 


\subsection{Advantages}

- Radiators are not subjected to compressive loads, as flange to flange type clamping system is adopted.

- Easy loading of radiator and pneumatic clamping system for sealing between dummy tank and body.

- This technique offers leakage detection accuracy in the $10^{-3} \mathrm{~Pa} \cdot \mathrm{m}^{3} / \mathrm{s}$ range

- It is especially useful in high volume applications, and leak detection and location is very economical

\subsection{Disadvantages}

- It has relatively low sensitivity

- Depends on the skill of the operator

- There can be a minor possibility of part Contamination.

\subsection{Applications}

- Very widely used in the automotive industries for the leakage testing of radiators.

- Used in the refrigeration industry

\section{Discussion}

In this paper, we have finalized the design for piston. The piston is used for generating the up and down movement of the platform which will bear the loads of the various radiators, which are selected for leakage testing. The piston movement is controlled with the help of the pneumatic timer circuit, which we have designed by using the SMC software. The designs for the tank and platform have been finalized. We have almost completed the entire design with only the support legs remaining. The theory regarding it has been finalized and the design will be confirmed as the final part of this procedure. A visit to the "Tata Toyo Radiator Ltd" campus has been planned to observe the testing of the machine and draw the final conclusions regarding the performance of the machine.

\section{Acknowledgement}

The authors are grateful for the support given by the Head of Department, Mechanical Engineering Department and the Principal, MITCOE, Pune.

\section{Nomenclature}

$S \quad$ Leakage sensitivity

$p \quad$ Applied pressure

$V \quad$ Internal Volume of the bubble

$t \quad$ Time in seconds

$R \quad$ Radius of the bubble

$A_{p} \quad$ Area of platform

$W_{r} \quad$ Weight of radiator

$V_{p} \quad$ Volume of platform

$T$ Thickness of platform

$V_{r} \quad$ Reduced volume

$m_{p} \quad$ Mass of platform

$d_{b} \quad$ Bore diameter

T' Tank thickness

\section{References}

Nylander(2005),Leak Testing with Hydrogen, Assembly Magazine, pg.23-24

Weber(2001), Advanced Leak Test Methods, Assembly Magazine, pg.14-15

S.B. Kakuts (2014), Review paper on Leak Detection,pg.12-13

Pregelj Andrej(1999), Leak Detection Methods, $4^{\text {th }}$ International Conference for NDT Testing,pg.25-26

Percy Gray, Jefferson, Lined tank and method of construction and leakage testing

Kanti K Mahajan, (2007), Design of process equipment, pg.100-101

Eugene Megyesy, (2009), Pressure vessel handbook, pg.125 130

Roark and Young, (2007), Formulae for stress and strain pg.76-80

PSG Design data book, pg.67-7

V.B. Bhandari, (2013), Design of Machine Elements,TMH Pub.,pg. 57-63

Company TQC: Product leaflets, Nottingham ,UK

https://www.FESTO.com> cat > DNC_ENUS

https://www.lacotech.com 